\section{Early Scientific Books}

Natural Science Books in English 1600 1900. By David Knight. Pp. $\mathrm{x}+262$. (B. T. Batsford: London, June 1972.) £6.50.

A CRITIC's task is to criticize, and the book is rare indeed that attracts no adverse comment. David Knight's Natural Science Books in English 16001900 is no exception, but let it be said at once that it deserves a general welcome as a knowledgeable and authoritative work that brings together a great deal of related, but widely dispersed, information. Briefly, the author offers us an eminently readable account of three centuries of science as recorded in books in the English language. The richness of this literature-which derives by no means only from Britain-is such that the story is remarkably comprehensive. His treatment is liberal: included are not only foreign scientific books translated into English, but many works on technology and a fair number of journals. Each chapter is followed by lists of original sources and of relevant recent publications. It is not a book for the specialist - when he is specializing, that is: but often enough the specialist puts himself on a par with the ordinary citizen and merely wants, in the first instance at least, some general information. A detailed index makes it easy to find any particular reference, and the general bibliographies help to smooth the way for those who wish to delve deeper. There are nearly a hundred illustrations from the books mentioned, a few in colour but most in black-and-white.

The book will certainly be of lasting value to the historian of science as a reference book. As the publishers claim, it will be useful also to the collector, but its value in this respect will be decidedly more limited. Apart from aesthetic considerations, and the special question of annotation, the value of a book to the scholar lies very largely in the text; a good facsimile edition, of which there are now very many in this field, is almost as useful as the original. Indeed, many early scientific books are now so rare that it is by no means easy to have access, whether by purchase or loan, to originals. The collector's interest is very different: his concern is with such subtleties as paper size, binding, pagination and illustrations, number of copies printed, special editions, pirated editions, and the like. On such points the bibliographies as here presented are silent: the information given is, in general, limited to author and title and year and place of publication of the first edition. While the inclusion of more information would greatly have increased the value of the book to the collector, it would undeniably have added considerably to the labour involved and to the size (and price) of the book. However, even as it is the collector can at least gain some preliminary information about an unfamiliar work.

As the roots of the book extend back a little before 1600 , so the later chapters, and a short epilogue, take it a little beyond 1900 . This rounding off at either end ensures continuity of treatment for the main period.

TREVOR I. WIILIAMS

\section{Enumeration}

Combinatorics. By N. Ya Vilenkin. Translated by A. Shenitzer. Pp. xiii + 296. (Academic: New York and London, August 1971.) £5.60; $\$ 12$.

THIs book was published in Moscow in 1969, and the present translation appeared in 1971. It deals with a branch of enumerative algebra which was important in the early decades of this century, then came under a decline, and now, in recent decades, has achieved increasing importance with the development of combinatorial mathematics. The author carefully explains various methods of enumeration and pays special attention to recurrence relations and generating functions. The use of partitions and geometric methods is emphasized.

The text is essentially elementary and an outstanding feature is the inclusion of a large number of illustrative problems with solutions. These problems are drawn from many diverse sources, including reference to random walk, Brownian motion and information theory. A number of problems relating to a chess board are solved. Finally, there is a list of more than 400 problems together with hints for their solution.

Combinatorial mathematics is relevant in a large variety of present-day mathematical situations. Examples of applied fields include mathematical programming, statistics, production planning, and computing. In pure mathematics one might mention finite and enumerative geometry, combinatorial geometry, and various parts of algebra such as group theory, representation theory and nonassociative algebras. The truth is that the concept of continuity and its consequences no longer form the only dominant theme in mathematics. Theories of discreteness, and many practical situations of a discrete character, are much to the fore these days, and the term "finite mathematics" has come to achieve a significance and importance unknown even two or three decades ago. As a result, the book under review appears at a most appropriate time, and it will appeal to a wide variety of readers. L. S. GoDDARD

\section{Drug Monograph}

Drugs and Driving: a Survey of the Relationship of Adverse Drug Reactions. By Gerald Milner. Vol. 1. Pp. $x i+124$. (S. Karger: Basle, London and New York, 1972.) £3.30; \$7.20.

As the author indicates, this is an area of growing importance, in which it is difficult to keep abreast of all research findings. The first chapter is of interest mainly to the general reader wishing to inform himself about the basic psychotropic drugs which may affect driving performance. The approach is sometimes polemical; for example, accident rates attributed to alcohol are quoted from a road safety booklet. The useful table of psychotropic drugs is somewhat idiosyncratic, for it lists five tricyclic antidepressants, three with identical doses, indications and side effects, but omits any mention of the opiates and hallucinogenic drugs; and amongst the stimulants, it ignores the amphetamines in favour of methylphenidate (perhaps representing Australian restrictions on the prescribing of amphetamines, which are not world wide). The second chapter is directed to the research worker particularly concerned with methodological aspects of research in this field. The examples, from the author's own experimental work into the effects of drug-alcohol interactions in animals and humans, and experiments with driving simulators, are particularly interesting; although here the section on the risk of liver damage from tricyclic antidepressants and alcohol seems curiously unrelated to the effects of such drugs on driving. The final chapter, summing up the existing knowledge in this field, is certainly relevant to the medical practitioner with a responsibility towards his patients to whom he may prescribe psycho-active drugs. The impairment of driving abilities seems to occur particularly during the early stages of treatment and is particularly marked when drugs are given in combination with alcohol, because of the risk of potentiation. The advice given to a patient receiving such drugs can now be based on increasing factual knowledge. Given the amount of such valuable information that is provided in this book, one wonders once again why it is necessary to include less relevant facts, such as the suicidal risk of tricyclic drug overdose; the consequences of wearing contact lenses at night; the complications of diabetes and the value of safety belts. While these obviously have relevance either to prescribing or to road safety, they seem out of context in this monograph. Overall, this is a wide ranging and interesting personal survey of the field of drugalcohol interaction and driving by an author well qualified in the subject. It 